\title{
MicroRNA (miRNA) and the immune system
}

\author{
BEATA HUKOWSKA-SZEMATOWICZ', BEATA TOKARZ-DEPTUŁA ${ }^{\prime}$, WIESEAW DEPTUŁA ${ }^{2}$
}

${ }^{1}$ Department of Immunology, Faculty of Biology, University of Szczecin, Poland

${ }^{2}$ Department of Microbiology, Faculty of Biology, University of Szczecin, Poland

\begin{abstract}
During the last few years, several types of small regulatory RNA-sRNA have been described, which participate in gene silencing. So far, the largest group of SRNA described is microRNA, which are multifunctional molecules that participate in many physiological and pathological processes in mammals. As it turns out, the molecules are also related to the immune system, and their participation was described in both innate and adaptive immunity.
\end{abstract}

Key words: microRNA, immune system, HSCs, innate immunity, adaptive immunity.

(Centr Eur J Immunol 2012; 37 (4): 387-390)

\section{Introduction}

Recent studies have led to description of several types of srRNA (small regulatory RNA), which participate in the posttranscription gene silencing, which refers to microRNA (miRNA) or transcription and post-transcription phase in the case of siRNA (small interfering RNA). Among the two basic regulatory RNA, miRNA occur in vertebrae, insects, plants, fungi, unicellular organisms, viruses, whereas siRNA in animals, plants, fungi and ciliates.

Within siRNA, there are 9 specialised molecules, and these include rasiRNA (repeat-associated small interfering RNA) (plants), tasiRNA (trans-acting small interfering RNA) (plants), exogenous siRNA (exogenous small interfering RNA) (animals, plants, fungi), ha-siRNA (heterochromatinassociated small interfering RNA) (plants, fungi), nat-siRNA (natural antisense small interfering RNA) (plants), and scnsiRNA (siRNA-like scan [scn] RNA) (ciliates) and casiRNA (cis-acting-siRNA) (plants) [1-5], piRNA (piwi-interacting RNA) (Drosophila melanogaster, Caenorhabditis elegans and Apodemus agrarius) [6, 7], as well as tsRNA (tRNAderived small RNA), present in humans [8].

A group larger than siRNA is formed by miRNA, as 16800 sequences of such molecules have been described so far. Their genes have various location, and are present in introns and/or exons of structural genes or in areas between genes [3]. For the first time, the molecules were described in the 1990s, during the studies on development phases of Caenorhabditis elegans. It was then discovered that in this nematode, correct transition from the first larval stadium into the second and fourth stadium - the mature form, is the responsibility of short RNA molecules, lin-4 and let-7, later referred to as miRNA [4]. Further miRNA were described for Drosophila melanogaster, Danio rerio, and Apodemus agrarius [9]. The mechanism for translation attenuation as a result of antisense RNA and mRNA, recorded in the early 1990s, was confirmed in 1998, when Andrew Z. Fire and Craig C. Mello discovered the phenomenon of RNAi (RNA interference) [10], for which in 2006 they were honoured with the Nobel Prize in the area of biology and medicine. At that time, multiplicity of miRNA molecules were found, yet they varied with the nucleotide sequence, expression profile and participation in the post-transcription regulation of gene expression [11]. At present, in the Internet miRNA base - mirbase [12], as mentioned, there is information about 16800 miRNA sequences described in animals, plants, fungi and viruses, whereas 1424 of them have been described in humans, 13144 in animals, and 3656 in plants, fungi and viruses [12]. It was evidenced that about $2 \%$ of genes known in humans encode miRNA, whereas one type of miRNA may be responsible for regulation of about 200 genes [13]. MicroRNA are multifunctional molecules that play a major role in mammals in many physiological and pathological processes. Such processes include differentiation of stem cells of the haematopoietic system, haematopoiesis, differentiation of skeletal muscles, embryogenesis, neurogenesis, angiogenesis, exocytosis, apoptosis, regulation of xenobiotic metabolism, regulation of insulin secretion, differentiation of adipocytes and inflammations, carcinogenesis, viral and bacterial infections, as well as cardiovascular and neu-

Correspondence: Dr Beata Hukowska-Szematowicz, Department of Immunology, Faculty of Biology, University of Szczecin, Z. Felczaka 3 A, 71-412 Szczecin, e-mail: beatahukowska@ poczta.onet.pl 
rological diseases, as well as autoimmunisation process [9, 14-16]. At present, it is known that about 100 miRNAs undergo expression in cells forming the immune system $[14,17]$ and play a key role in their development, including innate and acquired immunity. Despite the fact that all the aforementioned functions of miRNA, in particular the connection of miRNA with the immune system, have been described in the last 15 years, the indications of possible regulation of the immunological response by RNA appeared as early as in the 1950s [18], as at that time TF (transfer factor) was isolated from leukocytes of allergic animals, which is capable of transmitting immunological information onto nadve individuals. In practice, this meant that contact with antigen of an individual who had previously received TF allowed for stimulating secondary immunological response [18]. As a consequence of further studies, it was determined that TF is composed of small two-strand RNA, which is fissured at the temperature of $90 \mathrm{C}$, just as in the case of primary RNA fissure to precursor miRNA. The studies on the possibility of therapeutic application of TF lasted until the 1980s, and their results were rather treated as curiosity [18].

\section{Biogenesis of miRNA and mechanism of action}

Owing to the present achievements of molecular biology and studies on many organisms, the biogenesis and cellular function of mammal miRNA is rather well-known $[2,11,19,20]$. It was evidenced that miRNA is transcribed principally by polymerase II RNA, which generates primary transcripts - pri-miRNA $[11,19]$. In the nucleus, primary transcripts of miRNA (pri-miRNA), are transformed into pre-miRNA, which is regulated inter alia by Drosha enzyme. Next, pre-miRNA in conjunction with nuclear transport protein - exportin 5, transfers into cytoplasm, where further processing of the precursor molecule occurs with participation of Dicer enzyme [11]. Dicer enzyme recognises two-strand pre-miRNA and cuts this duplex, as a result of which twostrand RNA are formed with the length of 22 nucleotides, remaining within the RISC complex. The complex recognises guide strand of RNA duplex, which, after degradation of the other strand, becomes mature miRNA, which is transported by importin 8 to specific place in the cell $[11,15]$. It was evidenced that miRNA expression and function is regulated during transcription, maturation and location of the molecule within the cell, but also impacts on inflammations and stress $[11,19]$. MicroRNA expression is also regulated by transcription factors that may be activated during immunological response by ligands of Toll-like receptors (TLR) [21] and by antigens and cytokines [22].

\section{MicroRNA and haematopoietic stem cells}

Haematopoietic stem cells (HSCs) present in the bone marrow give origin to all lines of blood cells, including cells forming the immune system. Hematopoietic cells must keep precise balance between self-renewal and differentiation i.a. into lymphocytic and myeloid line of hematopoietic system cells [14, 23]. As evidenced, miRNA already mediates in the regulation of early development of HSCs cells [14, 23]. It was proved that miRNA may inhibit expression of relevant genes of haematopoietic cells and impact on production of haematopoietic progenitor cells, and may be involved in HSCs biology [14]. It was evidenced that in loci of HOX (homeobox genes), which play major role in the regulation of HSCs homeostase, there are miRNA from miRNA196 and miRNA-10 families, which may directly inhibit expression of HOX, similarly as in the case of miRNA-126, which inhibits gene responsible for expression of progenitor cells, HOXA9 [14]. In turn, miRNA-221 and miRNA-222 molecules regulate expression of KIT (tyrosine kinase gene), which affect homeostase of (multipotential) stem cells.

\section{MicroRNA and innate immunity}

Innate immunity cells, such as granulocytes, monocytes, macrophages, dendritic cells, form the first line of defence against infections [24]. It turns out that miRNA molecules play a major role in generation and functioning of various types of cells, from which granulocytes, monocytes, macrophages, NK cells and some antigen-presenting cells are formed, including dendritic cells. It was also evidenced that this is influenced by activity resulting from interaction between miRNA and relevant transcription factors [14].

Granulocytes. The cells are formed from myeloid line under the impact of GFI1 (grow factor independent 1) [25]. It was evidenced that GFI1 binds to promoter region of primary transcripts pri-miRNA-21 and pri-miRNA-196b, and inhibits their expression, whereas overexpression of miRNA-21 and miRNA-196, blocks granulocytepoesis in vitro [25]. Apart from miRNA impact on regulation of granulocyte development, the molecules impact on their function, as it was evidenced that miRNA-223 induced by myeloid transcription factor PU.1 and transcription factor binding to CCAAT sequence, acts as negative regulator of proliferation and activation of neutrophils [26].

Monocytes. The cells, and principally their development, depend on miRNA, although also during differentiation of human haematopoietic progenitor cells towards monocytes, it was recorded that decrease in the level of their expression is related to miRNA-17-5p, miRNA-20a, miRNA-106a, miRNA-17-92, miRNA-106a-92 [27]. It was also evidenced that miRNA-17-92 group inhibits production of RUNX1 (runt-related transcription factor 1), which, during monocytopoesis, regulates the expression of CSFR (colony stimulating factor receptor) [27]. In turn, miRNA424 and miRNA-155 are considered as promoters of monocyte differentiation, as the earlier inhibits expression of NFIA (nuclear factor I/A) [14, 27], while increased expression of the latter (miRNA-155) in monocytes was found after their stimulation by TLRs [14]. 
Macrophages. The elements, similarly as granulocytes and monocytes, in the area of differentiation and functioning, also depend on miRNA. It was evidenced that the cells, occurring in the inflammation area due to e.g. infection, are characterised with increased differentiation of miRNA, among which miRNA-155, miRNA-146a and miRNA146b, miRNA-147, miRNA-125b, and miRNA-21 were observed $[21,22,28]$. In the case of the best described molecule miRNA-155, it was determined that their high expression occurs in macrophages, after stimulation with lipopolysaccharides (LPS), which led to increased synthesis of pro-inflammatory cytokines, e.g. tumor necrosis factor $\alpha$ (TNF- $\alpha$ ) and interferon $\beta$ (IFN- $\beta$ ) [22]. In turn, in the case of miRNA-146 and miRNA-147, it was evidenced that in macrophages they regulate expression of IRAK1 (interleukin-1 receptor-associated kinase 1), IRAK2 (interleukin-1 receptor-associated kinase 2) (genes encoding receptors for IL-1 and IL-2) and TRAF6b (TNF receptor-associated factor 6b) [21]. Furthermore, it was observed that miRNA21 and miRNA-125b enhance macrophage activation [28], whereas the latter molecule is responsible for generation of activated and mature macrophages probably through partial decrease in the level of IRF4 (interferon regulatory factor 4) [28].

Dendritic cells. The development, differentiation and functioning of such leucocytes is influenced by many specific miRNA, such as miRNA-21, miRNA-34a, miRNA148 family, miRNA-155, miRNA-221 and miRNA-222, miRNA-142-3p, miRNA-146a [29]. It was evidenced that miRNA-21, miRNA-34a molecules, present during differentiation of dendritic cells may inhibit expression of JAG1 (jagged1) gene, the product of which is necessary for dendritic cells differentiation. The expression of miRNA-148 was recorded during maturation of dendritic cells that impact on regulation of the process of antigen presentation to dendritic cells and on cytokine production. MicroRNA155 , appearing during maturation of dendritic cells, impacts on the change of expression and their markers, and on cytokine production [29]. The studies also indicate that expression of miRNA-221 and miRNA-222 is necessary for maturation of dendritic cells [29], while in nature dendritic cells, expression of miRNA-142-3p inhibits the synthesis of IL-6. In turn, expression of miRNA-146a in Langerhans cells is related to inhibition of signals from TLRs present in such cells [29].

Natural killer cells. These elements, as very important cells of the immune system, principally in the fight against tumours and viral infections, depend on miRNA in the area of development and functioning. It was evidenced that the effectiveness of development of natural killer (NK) cells in humans principally depends on the level of miRNA-181a and miRNA-181b [30]. Furthermore, in the same study, it was recorded that overexpression of miRNA-181a/b conditions increased production of IFN- $\gamma$ by NK cells [30]. Results of the latest studies indicate that miRNA-155 par- ticipates in the regulation of cytotoxicity of human NK cells, because over-expression of this molecule has been observed in NK cells during their cidal capacity; although the mechanism of this process is not entirely known. Overexpression of miRNA-155 outstandingly increased during the lysis of target cells and degranulation of NK cells, whereas inhibition of miRNA-155 resulted in the decrease in such activity [31].

\section{MicroRNA and adaptive immunity}

The development of adaptive immunity, related to many subpopulations of lymphocytes $\mathrm{T}$ and lymphocytes $\mathrm{B}$, is controlled by signalling complexes of protein connections (or complexes of network signalling proteins), subject to regulation by miRNA, and the process occurs both during their development and during their functioning [14].

T-cells. In the case of these lymphocytes, it was evidenced that miRNA production by Dicer enzyme is necessary for effective development of T-cells in vivo, many subpopulations of which condition adaptive immunity. It was determined that among subpopulations of T-cells, there is a broad range of expression of molecules from the miRNA group, which templates of miRNA expression are recorded for various subpopulations and in their development phases [14]. Furthermore, several variants of miRNA were discovered in the very T-cells, where mature miRNA have terminal 3' or 5 ' of various length, or contain mutated sequences. The studies prove that miRNA mediates in target regulation of T-cells, and this is a dynamic process. It was evidenced that miRNA17-92 group comprises highly conservative molecules that affect the process of lymphocyte $\mathrm{T}$ production and selection [14]. Moreover, it was determined that miRNA-181a in mammals is responsible for correct development of T-cells and participates in the T-cells' response to antigens [14]. In turn, miRNA-155 affects differentiation of T-cells, and its binding point is transcription factor of IL-2 - basic cytokine for T-cell differentiation into Th1. In the absence of miRNA155 , there is no development of naive T-cells into Th2, and this is related to production of IL-4, IL-5 and IL-10 [18]. Furthermore, shortage of miRNA-155 in T-cells is the cause for their incorrect activity in inflammatory response, which is manifested by reduced secretion of IL-2 and INF- $\alpha[14,18]$. Furthermore, with miRNA-155, there is inhibited expression of SOCS1 (suppressor of cytokine signaling 1). It was also determined in vitro that miRNA-326, regulating differentiation of lymphocytes $\mathrm{T}_{\mathrm{H}} 17$, also participates in the pathogenesis of sclerosis multiplex [32]. It was also evidenced that regulator T-cells $\left(\mathrm{T}_{\mathrm{reg}}\right)$, which affect and regulate the autoimmunisation process, also depend on many types of miRNA, e.g. miRNA-155 and miRNA-142-3p [14].

B-cells. As indicated by the studies, generation and maturation of B-cells requires participation of miRNA, as in animals with shortage of Dicer enzyme, irregularities in development of B-cells were recorded, related to the defect 
of transition of progenitor B cells (proB) into precursor (preB) B cells [14]. In other studies [18] it was evidenced that it is miRNA-155 that plays the key role in the regulation of B-cell response, as overexpression of this type of miRNA was observed in lymphomas of B-cell origin, which caused a suspicion that this molecule is the regulator for such cells. In the case of miRNA-150 and miRNA-17-92 group, it was proved that they impact on early development of B-cells by inhibition of expression of $M Y B$ gene and BIM gene (BCL-2-like protein) [14].

\section{Conclusions}

MicroRNA is the key regulator in the development and functioning of many cells in the immune system, including granulocytes, monocytes, macrophages, dendritic cells, NK cells and T- and B-cells. The role of these molecules is significant both in innate and adaptive immunity. Owing to the fact that increasingly more specialised molecules are identified within this group, in the future it will be possible to define their role in a more precise and exhaustive manner, and thus know the biology of immune system cells better, which may also have practical implications.

\section{References}

1. Backofen R, Bernhart SH, Flamm C, et al. (2007): RNAs everywhere: genome-wide annotation of structured RNAs. J Exp Zool B Mol Dev Evol 308: 1-25.

2. Filip A (2007): MikroRNA: nowe mechanizmy regulacji ekspresji genów. Post Bioch 53: 413-419.

3. Li SC, Tang P, Lin WC (2007): Intronic micro-RNA: discovery and biological implications. DNA Cell Biol 26: 195-207.

4. Szweykowska-Kulińska Z, Szarzyńska B (2007): Nagroda Nobla 2006 za fundamentalne odkrycia w regulacji ekspresji genów u eukariontów. Post Biol Kom 1: 3-13.

5. Warkocki Z, Figlarowicz M (2006): Krótkie interferencyjne RNA działające in trans. Post Bioch 52: 253-259.

6. Ghildiyal M, Zamore PD (2009): Small silencing RNAs: an expanding universe. Nature 10: 94-108.

7. Kowalczykiewicz D, Wrzesiński J (2011): Rola piRNA oraz białek Piwi w regulacji rozwoju komórek płciowych. Post Bioch 57: 249-256.

8. Haussecker D, Huang Y, Lau A, et al. (2010): Human tRNAderived small RNAs in the global regulation of RNA silencing. RNA 16: 673-695.

9. Alvarez-Garcia I, Miska EA (2005): MicroRNA functions in animal development and human disease. Development 132: 4653-4662.

10. Fire A, Xu S, Montgomery MK, et al. (1998): Potent and specific genetic interference by double-stranded RNA in Caenorhabditis elegans. Nature 391: 806-811.

11. Ouellet DL, Perron MP, Gobeil LA, et al. (2006): MicroRNAs in gene regulation: when the smallest governs it all. J Biomed Biotechnol 2006: 69616.

12. miRBase Release 18. http://www.mirbase.org (data ostatniej aktualizacji 17.04.2012).

13. Kowal M (2007): Znaczenie mikroRNA w onkogenezie. Acta Haemat Pol 38: 275-290.
14. O'Connell RM, Rao DS, Chaudhuri AA, Baltimore D (2010): Physiological and pathological roles for microRNAs in the immune system. Nat Rev Immunol 10: 111-122.

15. Hukowska-Szematowicz B, Deptuła B (2010): Biologiczna rola mikroRNA (miRNA) - nowe dane. Post Biol Kom 37: $1-13$.

16. Boldin MP, Baltimore D (2012): MicroRNAs, new effectors and regulators of NF- $\kappa$ B. Immunol Rev 246: 205-220.

17. Baltimore D, Boldin MP, O'Connell RM, et al. (2008): MicroRNAs: new regulators of immune cell development and function. Nat Immunol 9: 839-845.

18. Sikora E, Ptak W, Bryniarski K (2011): Immunoregulacja poprzez interferencyjny RNA - mechanizmy, rola, perspektywy. Postepy Hig Med Dosw (on-line) 65: 482-495.

19. Bartel DP (2004): MicroRNAs: genomics, biogenesis, mechanism and function. Cell 116: 281-297.

20. Williams AE (2008): Functional aspect of animal microRNAs. Cell Mol Life Sci 65: 545-562.

21. Taganov KD, Boldin MP, Chang KJ, Baltimore D (2006): NF-kappaB-dependent induction of microRNA miR-146, aninhibitor targeted to signaling proteins of innate immune response. Proc Natl Acad Sci U S A 103: 12481-12486.

22. O'Connell RM, Taganov KD, Boldin MP, et al. (2007): MicroRNA-155 is induced during the macrophage inflammatory response. Proc Natl Acad Sci U S A 104: 1604-1609.

23. Gangaraju VK, Lin H (2009): MicroRNAs: key regulators of stem cells. Nat Rev Mol Cell Biol 10: 116-125.

24. Potempa J (2012): Posttranslational modifications in innate immunity. J Innate Immun 4: 119-120.

25. Velu CS, Baktula AM, Grimes HL (2009): Gfi1 regulated miR21 and miR196b to control myelopoiesis. Blood 113: 47204728.

26. Johnnidis JB, Harris MH, Wheeler RT, et al. (2008): Regulation of progenitor cell proliferation and granulocyte function by microRNA-223. Nature 451: 1125-1129.

27. Fontana L, Pelosi E, Greco P, et al. (2007): MicroRNAs 17-5p-20a-106a control monocytopoiesis through AML1 targeting and M-CSF receptor upregulation. Nat Cell Biol 9: 775-787.

28. Chaudhuri AA, So AY, Sinha N, et al. (2011): MicroRNA$125 \mathrm{~b}$ potentiates macrophage activation. J Immunol 187 : 5062-5068.

29. Turner ML, Schnorfeil FM, Brocker T (2011): MicroRNAs regulate dendritic cell differentiation and function. J Immunol 187: 3911-3917.

30. Cichocki F, Felices M, McCullar V, et al. (2011): Cutting edge: microRNA-181 promotes human NK cell development by regulating notch signaling. J Immunol 187: 6171-6175.

31. Liu X, Wang Y, Sun Q, et al. (2012): Identification of microRNA transcriptome involved in human natural killer cell activation. Immunol Lett 143: 208-217.

32. Du C, Liu C, Kang J, et al. (2009): MicroRNA miR-326 regulates TH-17 differentiation and is associated with the pathogenesis multiple sclerosis. Nat Immunol 10: 1252-1259. 